Research Article

\title{
Pitting Suppression of AISI 316 Stainless Steel Plates in Conditions of Ultrasonic Vibration
}

\author{
Georgii S. Vasyliev (iD) and Oleg M. Kuzmenko \\ National Technical University of Ukraine "Igor Sikorsky Kyiv Polytechnic Institute”, 37 Prospect Peremohy, Kyiv 03056, Ukraine \\ Correspondence should be addressed to Georgii S. Vasyliev; g.vasyliev@kpi.ua
}

Received 22 October 2020; Accepted 27 November 2020; Published 4 December 2020

Academic Editor: Maciej Jaskulski

Copyright (C) 2020 Georgii S. Vasyliev and Oleg M. Kuzmenko. This is an open access article distributed under the Creative Commons Attribution License, which permits unrestricted use, distribution, and reproduction in any medium, provided the original work is properly cited.

Plate heat exchangers are widespread type of equipment that suffers from pitting corrosion in chloride containing solutions. Anodic behaviour of AISI 316 stainless steel was tested in $3.5 \% \mathrm{NaCl}$ solution in conditions of ultrasound vibration $(27 \mathrm{kHz}$, $10 \mathrm{~W})$. The potentiodynamic sweep, potentiostatic technique, and galvanostatic technique were used coupled with surface morphology investigation after polarization. The pitting potential increased from $0.26 \pm 0.02 \mathrm{~V} / \mathrm{SSCE}$ to $0.42 \pm 0.05 \mathrm{~V} / \mathrm{SSCE}$, and repassivation potential increased from $0.03 \pm 0.01 \mathrm{~V} / \mathrm{SSCE}$ to $0.18 \pm 0.04 \mathrm{~V} / \mathrm{SSCE}$ when vibration was applied. The anodic current at applied potential in pitting region was two orders of magnitude lower in conditions of ultrasound vibration. A possible mechanism of vibration influence on pitting is proposed, which is the elimination of pit covers from the vibrating surface, vibration-induced electrolyte motion in and out of the pits, and repassivation of active metal inside the pits.

\section{Introduction}

Pitting corrosion is a major problem of metals in passive state operating in chloride containing solutions [1-4]. Surface defects and inclusions are the most common sites for pit initiation $[5,6]$, and pitting corrosion resistance is reduced at high flow rates [7]. The high corrosion rate, nonuniform pitting distribution, and high corrosion rate inside the pit cavity make this type of corrosion extremely dangerous, especially for thin metal parts. One of the examples of such equipment is plate heat exchangers. Thin stainless plates of $0.2-0.5 \mathrm{~mm}$ are assembled in one pack and the heat carrier pass between the plates at high velocity. The pitting corrosion of the steel can shorten the operation time of the heat exchanger to 1-2 years instead of a planned period of 25 years.

Pitting corrosion usually undergoes several consecutive stages, from pit initiation to stable pitting growth. The metal impurities, grain boundaries, and mechanical defects of the passive film are known to be pit initiation sites. Recent works showed that MnS inclusions play significant role in pit initiation. The pit initiates at the boundary between the MnS inclusion and steel matrix and grows with time [8-10]. Under applied stress, the dissolution of $\mathrm{MnS}$ inclusions and sensitized grain boundaries is accelerated [11]. Laser surface melting was found to significantly reduce the size of the sulphide inclusions and thus improve the pitting resistance of austenitic steel [12].

Different approaches were developed to reduce the pitting corrosion of stainless steel [13-18]. Recent investigations revealed that the application of ultrasound (US) cavitation is an efficient tool to suppress pitting corrosion of stainless steels. Wang studied the pitting suppression of SUS304 stainless steel in $3.5 \% \mathrm{NaCl}$ solution and found three times reduction of electric charge passing through the steel when it was under the influence of ultrasound cavitation [19]. When the influence of ultrasound on pitting initiation, growth, and repassivation was investigated, it was established that lower potentials at constant currents and higher currents at constant potential responded to ultrasound [20]. In further work, it was shown that US intensity, as well as the distance between the vibrator and the steel specimen significantly, influences the efficiency of pitting suppression. When the distance was equal to US wavelength, the pitting 
suppression efficiency was proportional to the intensity. At a constant intensity, the increase in distance resulted in the reduction of efficiency [21].

The mechanism of pitting suppression with the application of ultrasound is based on the removal of the corrosion products cover over the nucleated pit. Once the pit is initiated, its further growth depends greatly on the stability of the cover over the pit mouth [22-24]. Ultrasound cavitation produces collapsing bubbles that bring about high collapse power. This promotes a cleaning effect on the surface; thus, the corrosion products covering the metastable pits are removed from the surface and pits are passivated $[20,21,25,26]$.

However, high intensity ultrasound is able to remove not only the partially damaged passive film but also the regular film, thus accelerating the corrosion rate. The simultaneous action of high intensity ultrasound and corrosive environment accelerates steel degradation [27-29]. The ultrasonic cavitation makes the outer layer of the passive film damaged, and the corrosion rate is accelerated [30]. Lavigne observed that passive films formed for $1 \mathrm{~h}$ under potentiostatic polarization and under ultrasonic conditions have more defects compared with those formed under silent conditions, which leads to a considerable decrease in the corrosion resistance of the sample [31]. Wan used $250 \mathrm{~W}$ ultrasound and found that cavitation accelerated the erosion of the ferrite in the corroded surface layer, resulting in the degradation of the nanomechanical properties of the corroded surface layer on stainless steel under cavitation [32]. The pitting corrosion was found to reduce fatigue behaviour of metals reducing the fatigue life by a factor of 10-100 [33].

Practical application of ultrasound to reduce pitting corrosion of stainless steel is limited by a short radius of cavitation field around the horn [34]. This work is aimed at the investigation of the anodic behaviour of AISI 316 stainless steel in conditions of ultrasound vibration instead of cavitation and possible mechanism of pitting suppression is proposed.

\section{Materials and Methods}

Commercially supplied AISI 316 steel plate of $0.5 \mathrm{~mm}$ thick was used in all the experiments. The steel composition was: C, 0.08 mass\%; Mn, 1.08; Si, 0.28; S, 0.02; P, 0.04; Cr, 16.1; Ni, 10.8; Mo, 2, 15; Fe balance. The steel sheet was cut into plates $20 \times 200 \mathrm{~mm}$. The plate was insulated, leaving a working area of $1 \mathrm{~cm}^{2}$ on one side of the plate. The surface of the plate was degreased with organic solvent and washed in flowing and distilled water.

The corrosion tests were carried out in a three-electrode cell connected to the potentiostat (Figure 1) [35, 36]. The working electrode was attached to the piezoelectric ultrasound transducer and connected to the ultrasound generator. A piece of glass ( $3 \mathrm{~mm}$ thick) was placed between the transducer and the steel plate to exclude any electrical contact. The input power of the ultrasound generator was $10 \mathrm{~W}$, and the ultrasound intensity was $0.35 \mathrm{~W} / \mathrm{cm}^{2}$ and US frequency $27 \mathrm{kHz}$. The low frequency ultrasound is widely used in industry to clean heat exchanging equipment from scale. Low intensity ultrasound was used to prevent any

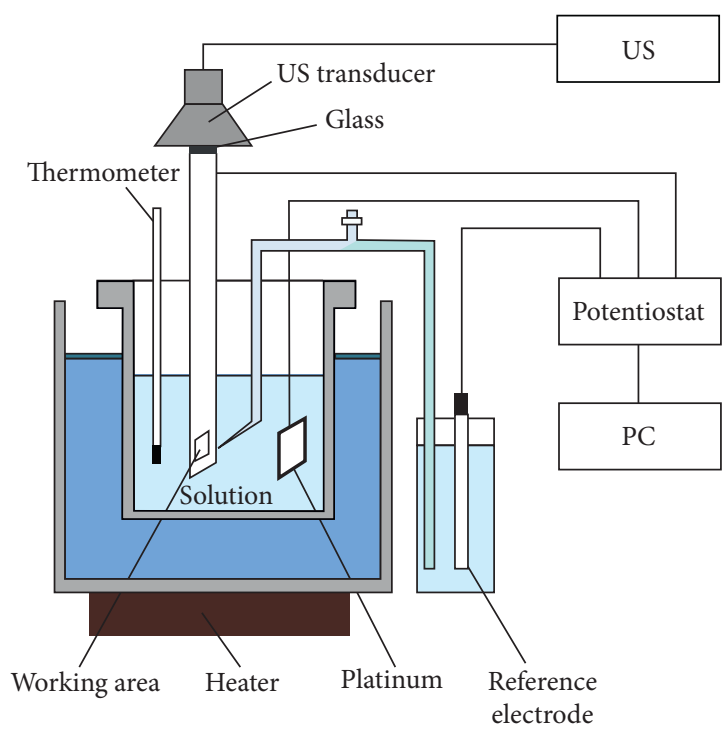

FIgURE 1: The scheme of laboratory set-up for corrosion testing in conditions of ultrasound vibration.

mechanical degradation of material due to erosion or fatigue. The ultrasound pressure was two orders of magnitude lower than the stress needed to cause fatigue fracture of the stainless steel [37]. The solution used in all the experiments was 3.5 mass $\% \mathrm{NaCl}$, and the temperature was maintained at $25^{\circ} \mathrm{C}$ using a water bath. A platinum plate was used as a counter electrode, and a saturated silver chloride electrode (SSCE) was used as a reference one.

Potentiodynamic polarization technique was used to determine the pitting potential $E_{\text {pit }}$ and repassivation potential $E_{\text {rep. }}$. The polarization started from the OCP to the anodic direction with the scan rate of $0.2 \mathrm{mV} / \mathrm{s}$. The nucleation of pits resulted in sharp current rise, and when the current value reached $100 \mu \mathrm{A} / \mathrm{cm}^{2}$, the polarization was reversed. The $E_{\text {pit }}$ was determined as a potential, where the current starts to increase. The $E_{\text {rep }}$ was determined in the reverse (cathodic) scan as a potential where the current in the reverse scan became lower than in the forward scan. In the tests with ultrasound, the steel plate was vibrated during the polarization. The tests were repeated five times to ensure data convergence. The experimental data in this work are presented by typical curves, and the values of $E_{\text {pit }}$ and $E_{\text {rep }}$ were averaged among five tests.

Once $E_{\text {pit }}$ was determined, the potentiostatic polarization technique was applied to compare the anodic current density with and without the application of ultrasound. The polarization started at the OCP and continued up to $0.3 \mathrm{~V} / \mathrm{SSCE}$ with the scan rate of $0.2 \mathrm{mV} / \mathrm{s}$. At $0.3 \mathrm{~V} / \mathrm{SSCE}$, the scan was stopped; potential was kept constant for $1 \mathrm{~h}$ and the anodic current was recorded. The holding potential of $0.3 \mathrm{~V} / \mathrm{SSCE}$ was selected, because in potentiodynamic polarization tests it was established that pitting is already initiated for the nonvibrated sample, while the vibrated one remains passive at this potential.

In the galvanostatic polarization method, the potential was determined as a function of time when a constant current was applied. The specimen was placed into the solution and held until the corrosion potential was 
established. Afterwards, a constant current density of $30 \mu \mathrm{A} / \mathrm{cm}^{2}$ was applied for $1800 \mathrm{sec}$ and the potential was recorded vs time. Every $1800 \mathrm{sec}$ the current density was increased in $30 \mu \mathrm{A} / \mathrm{cm}^{2}$, to constitute 60,90 , and finally $120 \mu \mathrm{A} / \mathrm{cm}^{2}$. The same procedure was performed in conditions of ultrasound vibration. The current density values for the galvanostatic test were selected in the range, where stable pitting corrosion occurs on the surface of the nonvibrated steel according to the potentiodynamic test.

After potentiostatic and galvanostatic polarizations, the working area of the steel surface was observed with the optical microscope to analyse the developed pits. The pit depth was measured using double focusing technique when the image is focused on the top of the surface and on the bottom of the pit. The difference in the focus distance is equal to the pit depth.

\section{Results and Discussion}

3.1. Potentiodynamic Polarization. Potentiodynamic polarization is used to determine the values of pitting potential $E_{\text {pit }}$ and repassivation potential $E_{\text {rep. The first one refers to }}$ the breakdown of the passive film, while the second one characterizes the total passivation of the pits formed above this potential. Typical potentiodynamic curves are given in Figure 2, and the $E_{\text {pit }}$ and $E_{\text {rep }}$ values, obtained in all the tests, are presented in Table 1.

In the absence of ultrasound vibration, the steel remains passive until the potential is below $0.1 \mathrm{~V} /$ SSCE. After this potential, several current fluctuations are observed that led to the steady current growth once the potential reaches $0.2 \mathrm{~V} / \mathrm{SSCE}$. When the current density reached $0.1 \mathrm{~mA} / \mathrm{cm}^{2}$, the polarization direction was shifted from anodic to cathodic. However, the current continued to grow as pitting was initiated. At the maximum, the current density values reached $0.3 \mathrm{~mA} / \mathrm{cm}^{2}$. In the reverse scan, after the potential of $0.16 \mathrm{~V} / \mathrm{SSCE}$, the current decreased and the $E_{\text {rep }}$ was reached at $0.03 \pm 0.01 \mathrm{~V} / \mathrm{SSCE}$.

Another situation is observed for the vibrating specimen. The current below $1 \mu \mathrm{A} / \mathrm{cm}^{2}$ is observed until the potential is below $0.42 \pm 0.05 \mathrm{~V} / \mathrm{SSCE}$. After this potential, the current starts to grow rapidly, even when the scan direction is reversed. The maximum current value is reached at $0.35 \mathrm{~V} / \mathrm{SSCE}$. There are several current peaks below this potential, but each following peak was lower showing the current tendency to decrease. Finally, the steel passivated at $0.18 \pm 0.04 \mathrm{~V} / \mathrm{SSCE}$.

Comparing the pitting potentials $E_{\text {pit }}$ and repassivation potentials $E_{\text {rep }}$ with and without ultrasound, it is clearly seen that US vibration increased the $E_{\text {pit }}$ in $0.16 \mathrm{~V}$ from $0.26 \pm 0.02 \mathrm{~V} / S S C E$ to $0.42 \pm 0.05 \mathrm{~V} / S S C E$ and $E_{\text {rep }}$ in $0.15 \mathrm{~V}$ from $0.03 \pm 0.01 \mathrm{~V} / S S C E$ to $0.18 \pm 0.04 \mathrm{~V} / S S C E$ to the anodic side. Thus, ultrasound vibration appeared to be a strong pitting suppression factor.

3.2. Potentiosatic Polarization. Potentiostaic polarization was performed to compare the anodic behaviour of vibrated and nonvibrated steel (Figure 3). For the nonvibrated steel,

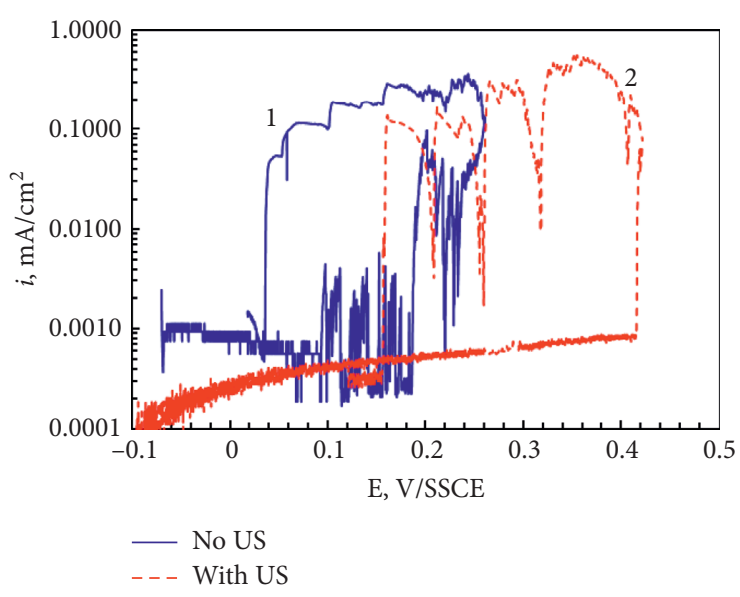

FIgUre 2: Potentiodynamic sweep of AISI 316 stainless steel in $3.5 \%$ $\mathrm{NaCl}$ solution. 1: nonvibrated; 2: vibrated. Sweep rate: $0.2 \mathrm{mV} / \mathrm{s}$. Ultrasound parameters: frequency $27 \mathrm{kHz}$, power $10 \mathrm{~W}$.

TABLE 1: The pitting potential $E_{\text {pit }}$ and repassivation potential $E_{\text {rep }}$ of the AISI 316 steel in $3.5 \% \mathrm{NaCl}$ in vibrated and nonvibrated conditions.

\begin{tabular}{lcccc}
\hline Test number & \multicolumn{2}{c}{ Nonvibrated } & \multicolumn{2}{c}{ Vibrated } \\
& $\begin{array}{c}E_{\text {pit }}, \\
\text { V/SSCE }\end{array}$ & $\begin{array}{c}E_{\text {rep, }}, \\
\text { V/SSCE }\end{array}$ & $\begin{array}{c}E_{\text {pit }}, \\
\text { V/SSCE }\end{array}$ & $\begin{array}{c}E_{\text {rep }} \\
\text { V/SSCE }\end{array}$ \\
\hline 1 & 0.26 & 0.03 & 0.41 & 0.15 \\
2 & 0.26 & 0.04 & 0.45 & 0.19 \\
3 & 0.28 & 0.02 & 0.35 & 0.15 \\
4 & 0.25 & 0.04 & 0.47 & 0.22 \\
5 & 0.26 & 0.04 & 0.4 & 0.18 \\
Average & $0.26 \pm 0.02$ & $0.03 \pm 0.01$ & $0.42 \pm 0.05$ & $0.18 \pm 0.04$ \\
\hline
\end{tabular}

the current appeared at $0.24 \mathrm{~V} / \mathrm{SSCE}$ and raised slowly to reach the value of $0.25 \mathrm{~mA} / \mathrm{cm}^{2}$. After this, a sharp increase occurred, and the current reached the value of $5 \mathrm{~mA} / \mathrm{cm}^{2}$ and remained at this level.

For the vibrating steel, the current-time dependence shows a slow rise when the potential was scanned in the anodic direction. The current value stabilized at $0.03 \mathrm{~mA} / \mathrm{cm}^{2}$ when the potential becomes stable. Due to the vibration of the steel, current fluctuations were observed. Comparing the current values of vibrated and nonvibrated specimens, it can be clearly seen that ultrasound vibration reduces anodic current in the pitting region at least in 100 times.

3.3. Galvanostatic Polarization. During galvanostatic polarization, the minimum galvanostatic potential of pitting corrosion $E_{\mathrm{pc}}$ was determined when constant current was applied. In this test, a total of four current densities were tested, ranging from 30 to $120 \mu \mathrm{A} / \mathrm{cm}^{2}$ applied for $1800 \mathrm{sec}$ each.

The potential-time dependences are given in Figure 4. The current density of $30 \mu \mathrm{A} / \mathrm{cm}^{2}$ does not cause any significant changes in $E_{\mathrm{pc}}$ potential between the vibrated and nonvibrated specimens. At higher current densities, the $E_{\mathrm{pc}}$ value of nonvibrated steel is $0.02 \pm 0.02 \mathrm{~V} /$ SSCE. 


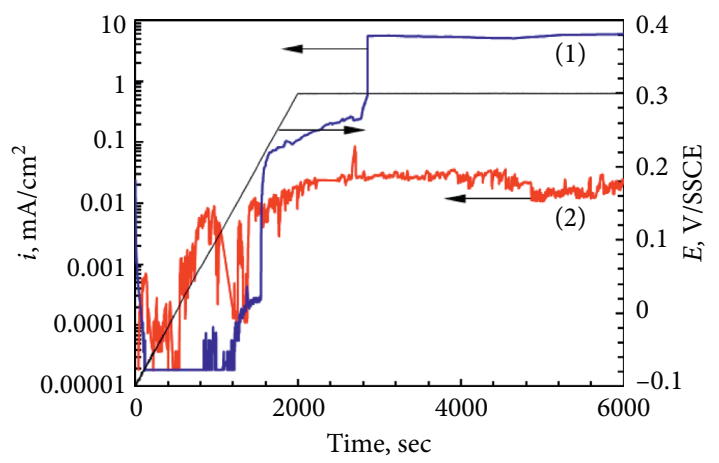

FIGURE 3: Potentiostatic polarization of AISI 316 stainless steel in $3.5 \% \mathrm{NaCl}$ solution. 1: nonvibrated; 2: vibrated. Applied potential $0.3 \mathrm{~V} / \mathrm{SSCE}$. Ultrasound parameters: frequency $27 \mathrm{kHz}$; power $10 \mathrm{~W}$.

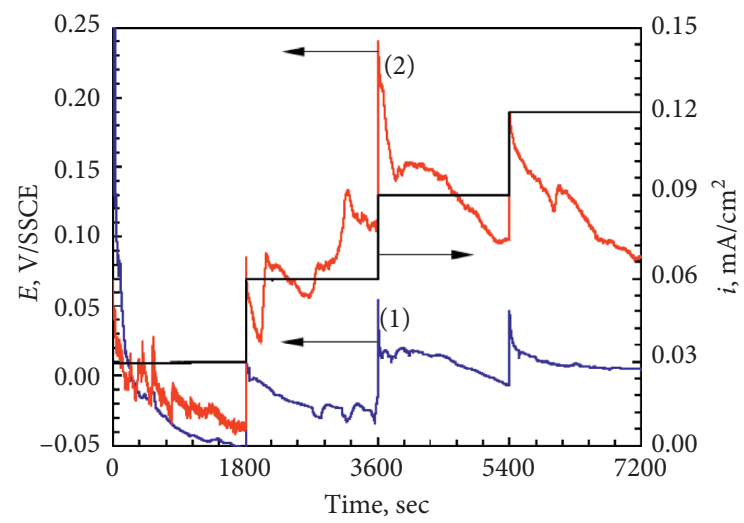

FIGURE 4: Galvanostatic polarization of AISI 316 stainless steel in 3.5\% $\mathrm{NaCl}$ solution. 1: nonvibrated; 2: vibrated. Applied current density $30-120 \mu \mathrm{A} / \mathrm{cm}^{2}$. Ultrasound parameters: frequency $27 \mathrm{kHz}$; power $10 \mathrm{~W}$.

Significantly more positive values were obtained for the vibrated steel. At the applied current density of $90 \mu \mathrm{A} / \mathrm{cm}^{2}$, the $E_{\mathrm{pc}}$ is $0.1 \pm 0.02 \mathrm{~V} / \mathrm{SSCE}$.

Comparing the results of potentiodynamic and galvanostatic polarization, the $E_{\text {pit }}$ values obtained in the potentiodynamic test are much higher, meaning the pitting initiation process is slower than the potential scan rate. However, the $E_{\text {rep }}$ values in potentiodynamic test are close to the value of $E_{\mathrm{pc}}$ in galvanostatic test for vibrated and nonvibrated specimens.

The micrographs of both vibrated and nonvibrated steel surfaces are given in Figure 5. For each sample, all the surfaces were analysed, and typical pitting regions are presented. Figure 5(a) shows the pit developed on nonvibrated steel during galvanostatic polarization. The corresponding potential-time dependence is shown in Figure 4. On the contrary, a series of much smaller defects was found on the surface of the vibrated steel after polarization in the same conditions (Figure 5(b)).

The same results were obtained in the potentiostatic polarization test. A pit of $1 \mathrm{~mm}$ in diameter and $20 \mu \mathrm{m}$ in depth was formed after $1 \mathrm{~h}$ of polarization at $0.3 \mathrm{~V} / \mathrm{SSCE}$
(Figure 5(c)). On the contrary, the surface of the vibrated steel shows no signs of dissolution. The results agree well with the current-time dependences, and higher anodic current values correspond to higher number of pits and the pits are deeper.

Pit morphology is known to be dependent on its growing conditions $[38,39]$. The higher anodic potential results in the opened pit with no pit cover [40]. In potentiostatic test at the applied potential of $+0.3 \mathrm{~V} / \mathrm{SSCE}$, the $600 \mu \mathrm{m}$ diameter pits are formed, with no covers, and are not dish-shaped (Figure 5(c)). Similar pit morphology was observed in galvanostatic test, but pit diameter was smaller $-300 \mu \mathrm{m}$ (Figure 5(a)). In conditions of ultrasound vibration, several tiny pits are formed with the diameters $10-20 \mu \mathrm{m}$ (Figure 5(b)) and they are dish-shaped, meaning ultrasound vibration removes the lacy covers over pit mouth.

3.4. Mechanism of Pitting Suppression. The possible mechanism of ultrasonic vibration influence on the local dissolution of stainless steel can be explained with the following scheme (Figure 6). According to the modern views, the pitting corrosion of metals in the passive state occurs in three consecutive stages [22]. The first one is pit nucleation (Figure 6(a)). Not all the nucleated pits can survive; only surviving pits enter the second stage, the metastable growth (Figure 6(b)). At this stage, the pitting growth is diffusioncontrolled. The continued survival depends on the maintenance of a cover over the pit that acts as a diffusion barrier. The cover may be formed by corrosion products of undermined passive film. The breakdown of this cover results in repassivation. All the pits that survive the metastable stage enter the third stage, stable growth (Figure 6(c)). Here, the diffusion barrier is formed inside the deep and narrow pit, where no solution stirring occurs, so the pit progress into the metal.

Several works were dedicated to the influence of pit cover removal on the repassivation of metastable pits [23]. In numerous studies in conditions of ultrasound cavitation, it was established that collapsing bubbles can ruin the pit cover, thus enhancing pit repassivation $[20,21,25,26]$. Therefore, the mechanism of pitting suppression, when ultrasound is applied to the solution, is cavitation erosion of the pit covers.

In conditions of ultrasound vibration, the cavitation is not the key factor. Ultrasound vibration is known to be widely used to clean the surface from any deposits [41-43]. Ultrasound vibration produces accelerations of $10^{4} \mathrm{~g}$. When the particle is attached to the vibrating surface, it is influenced by the vibration force originating from the piezoelectric transmitter, adhesion force, and inertia force. When the vibration is directed towards the solution (Figure 6(d)), the inertia force coincides with the adhesion force and the particle remains on the surface. However, when the vibration goes in the reverse direction, the inertia force is directed against the adhesion force. Therefore, any particles attached to the surface spall off once the inertia force exceeds the adhesion force (Figure 6(e)). For the stainless steel during pitting corrosion, such particles are lacy covers of 

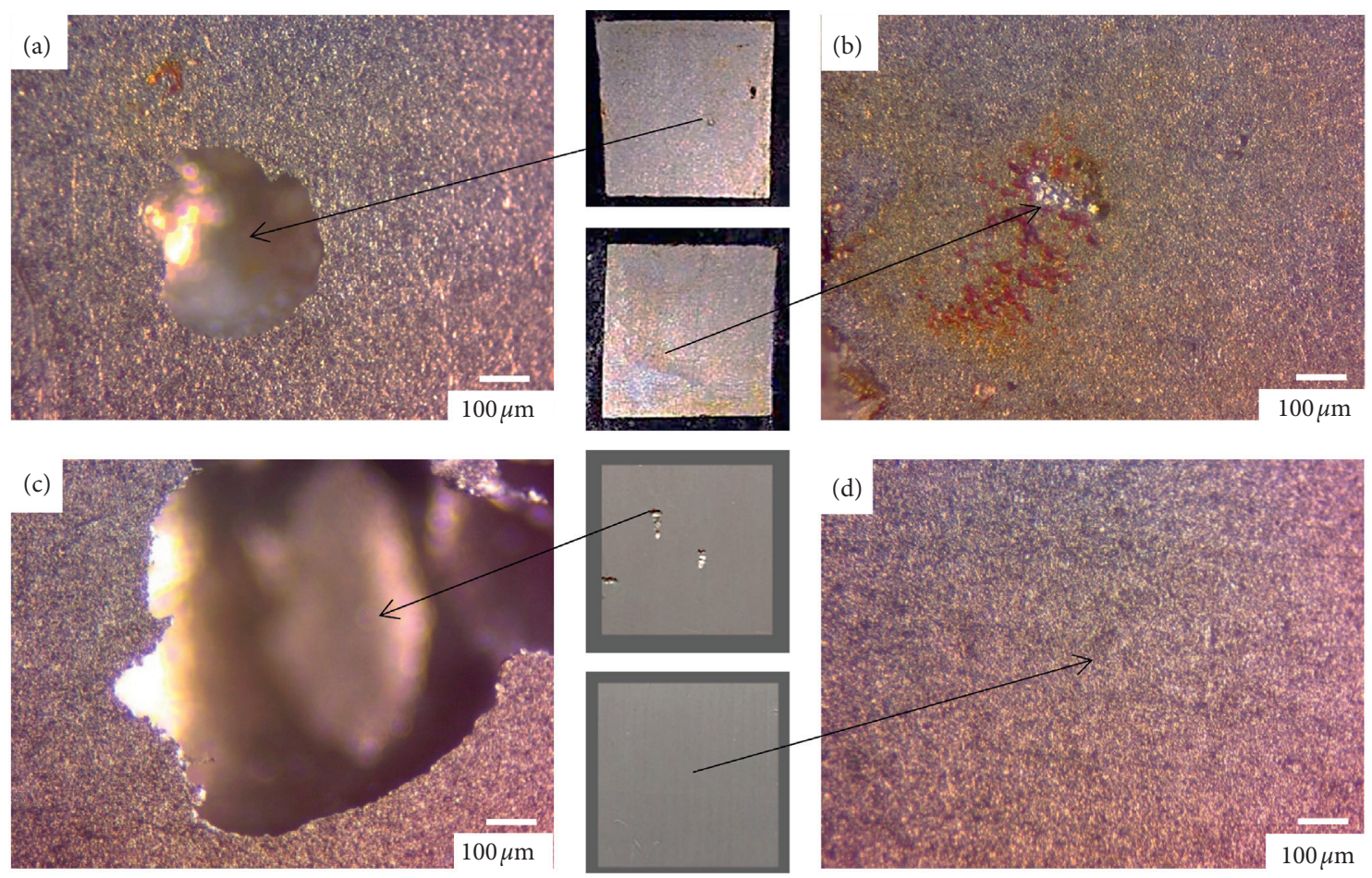

Figure 5: The surface of AISI 316 steel after galvanostatic $(a, b)$ and potentiostatic $(c, d)$ polarization in conditions of ultrasound vibration $(\mathrm{b}, \mathrm{d})$ and without vibration $(\mathrm{a}, \mathrm{c})$. Ultrasound parameters: frequency $27 \mathrm{kHz}$; power $10 \mathrm{~W}$.

Nonvibrated steel

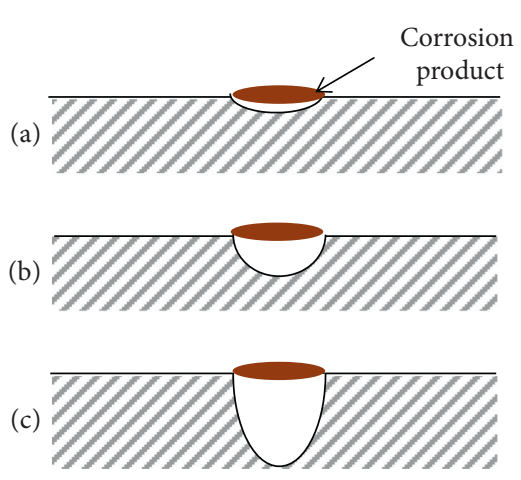

US-vibrated steel

(a)

(d)

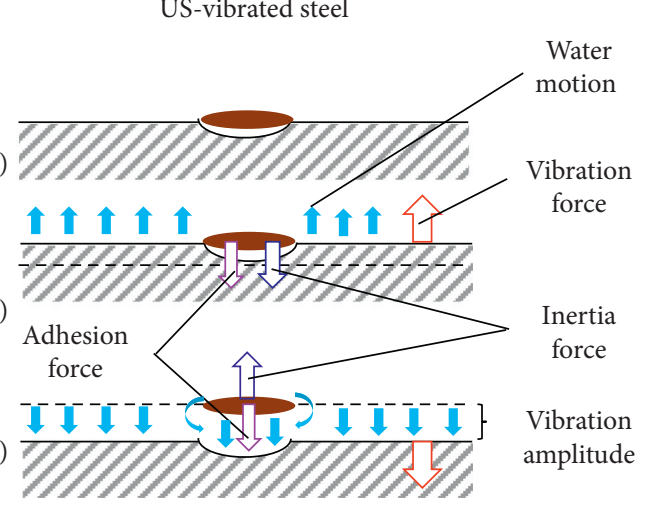

FIGURE 6: The scheme of pitting suppression with the application of ultrasound vibration: (a) pit nucleation; (b) metastable pitting; (c) stable pitting growth; $(d, e)$ influence of vibration.

undermined passive film over the formed pits. Moreover, continuous vibration may lead to the fatigue fracture of the corrosion cover. Once the protective cover over the metastable pits is removed, they passivate. The inertia force depends on the mass of the corrosion products and the vibration acceleration. In the present study, the mass of the cover over the pit appeared to be enough to be removed with ultrasound vibration at $27 \mathrm{kHz}$ and the power of $10 \mathrm{~W}$.

Another important part of pits repassivation under the influence of ultrasound vibration is related to the vibration induced electrolyte motion on the surface of the steel. The electrolyte contains constant oxygen concentration and when the surface is vibrating, fresh electrolyte moves in and out of the pits favouring fast repassivation of the inner surface of the pits. Any defects of the passive film breaking are recovered by rapid reaction of active metal with an oxygen saturated electrolyte. Moreover, fast and vigorous electrolyte movement near the surface facilitates the removal of lacy cover over the metastable pits. Moreover, the detached particles in the preelectrode layer, when moving with the electrolyte, act as an additional abrasive that cleans the surface from both newly formed pit covers and nonmetallic inclusions located at the surface that are known to be promoting the pitting corrosion. 


\section{Conclusions}

Application of ultrasound vibration is an efficient technique to reduce the pitting corrosion of AISI 316 steel in chloride containing solution, and this can be a promising approach to reduce the pitting corrosion of stainless steel parts in industrial plate heat exchangers. In addition, low amplitude ultrasound vibration is safe and does not cause fatigue fracture of the equipment.

The potentiodynamic polarization showed that the pitting potential was shifted to the anodic direction in $0.16 \mathrm{~V}$ from $0.26 \pm 0.02 \mathrm{~V} / \mathrm{SSCE}$ to $0.42 \pm 0.05 \mathrm{~V} / \mathrm{SSCE}$ and repassivation potential in $0.15 \mathrm{~V}$ from $0.03 \pm 0.01 \mathrm{~V} / \mathrm{SSCE}$ to $0.18 \pm 0.04 \mathrm{~V} / \mathrm{SSCE}$ in conditions of ultrasound vibration. Potentiostatic polarization of the steel in the pitting region showed two orders of magnitude current reduction when ultrasound vibration was applied. Surface analysis revealed practically no signs of dissolution for the vibrated steel, which confirms efficient pitting suppression with ultrasound vibration.

Possible mechanism of pitting suppression is the elimination of corrosion product covers over the pits. The detachment of corrosion products occurs when the inertia force appears under vibration and exceeds the adhesion force. Vibration-induced electrolyte motion leads to the further weakening of corrosion covers adhesion and promotes penetration of fresh oxygen-saturated electrolyte inside the pits that leads to the fast repassivation of the active metal.

\section{Data Availability}

All data generated or analysed during this study are included within the article.

\section{Conflicts of Interest}

The authors declare that they have no conflicts of interest.

\section{Acknowledgments}

This work was supported by the Ministry of Education and Science of Ukraine (grant nos. 2044 and 2017).

\section{References}

[1] N. Sridhar, "Local corrosion chemistry-a review," Corrosion, vol. 73, no. 1, pp. 18-30, 2017.

[2] Y. Wang, G. Cheng, and Y. Li, "Observation of the pitting corrosion and uniform corrosion for X80 steel in $3.5 \mathrm{wt} . \%$ $\mathrm{NaCl}$ solutions using in-situ and 3-D measuring microscope," Corrosion Science, vol. 111, pp. 508-517, 2016.

[3] A. Abbasi Aghuy, M. Zakeri, M. H. Moayed, and M. Mazinani, "Effect of grain size on pitting corrosion of 304L austenitic stainless steel," Corrosion Science, vol. 94, pp. 368-376, 2015.

[4] A. A. Dastgerdi, A. Brenna, M. Ormellese, M. Pedeferri, and F. Bolzoni, "Experimental design to study the influence of temperature, $\mathrm{pH}$, and chloride concentration on the pitting and crevice corrosion of UNS S30403 stainless steel," Corrosion Science, vol. 159, Article ID 108160, 2019.
[5] R. Oltra and V. Vignal, "Recent advances in local probe techniques in corrosion research-analysis of the role of stress on pitting sensitivity," Corrosion Science, vol. 49, no. 1, pp. 158-165, 2007.

[6] V. Vignal, H. Krawiec, O. Heintz, and R. Oltra, "The use of local electrochemical probes and surface analysis methods to study the electrochemical behaviour and pitting corrosion of stainless steels," Electrochimica Acta, vol. 52, no. 15, pp. 4994-5001, 2007.

[7] L. L. Li, Z. B. Wang, and Y. G. Zheng, "Interaction between pitting corrosion and critical flow velocity for erosion-corrosion of 304 stainless steel under jet slurry impingement," Corrosion Science, vol. 158, Article ID 108084, 2019.

[8] T. L. Sudesh, L. Wijesinghe, and D. J. Blackwood, "Real time pit initiation studies on stainless steels: the effect of sulphide inclusions," Corrosion Science, vol. 49, no. 4, pp. 1755-1764, 2007.

[9] N. Aouina, F. Balbaud-Célérier, F. Huet et al., "Single pit initiation on $316 \mathrm{~L}$ austenitic stainless steel using scanning electrochemical microscopy," Electrochimica Acta, vol. 56, no. 24, pp. 8589-8596, 2011.

[10] A. Chiba, I. Muto, Y. Sugawara, and N. Hara, "Direct observation of pit initiation process on type 304 stainless steel," Materials Transactions, vol. 55, no. 5, pp. 857-860, 2014.

[11] S. Tokuda, I. Muto, Y. Sugawara, and N. Hara, "Pit initiation on sensitized type 304 stainless steel under applied stress: correlation of stress, Cr-depletion, and inclusion dissolution," Corrosion Science, vol. 167, Article ID 108506, 2020.

[12] J. Stewart and D. E. Williams, "The initiation of pitting corrosion on austenitic stainless steel: on the role and importance of sulphide inclusions," Corrosion Science, vol. 33, no. 3, pp. 457-474, 1992.

[13] Y. Ait Albrimi, A. Ait Addi, J. Douch, R. M. Souto, and M. Hamdani, "Inhibition of the pitting corrosion of 304 stainless steel in $0.5 \mathrm{M}$ hydrochloric acid solution by heptamolybdate ions," Corrosion Science, vol. 90, pp. 522-528, 2015.

[14] M. Naghizadeh, D. Nakhaie, M. Zakeri, and M. H. Moayed, "The effect of dichromate ion on the pitting corrosion of AISI 316 stainless steel part II: pit initiation and transition to stability," Corrosion Science, vol. 94, pp. 420-427, 2015.

[15] M. Zakeri, D. Nakhaie, M. Naghizadeh, and M. H. Moayed, "The effect of dichromate ion on the pitting corrosion of AISI 316 stainless steel. part I: critical pitting temperature," Corrosion Science, vol. 93, pp. 234-241, 2015.

[16] M. Talebian, K. Raeissi, M. Atapour et al., "Pitting corrosion inhibition of 304 stainless steel in $\mathrm{NaCl}$ solution by three newly synthesized carboxylic Schiff bases," Corrosion Science, vol. 160, Article ID 108130, 2019.

[17] M. Bourguiba and A. Rebai, "Quelques techniques de groupement," European Journal of Operational Research, vol. 50, pp. 2-3, 2007.

[18] G. O. Ilevbare and G. T. Burstein, "The inhibition of pitting corrosion of stainless steels by chromate and molybdate ions," Corrosion Science, vol. 45, no. 7, pp. 1545-1569, 2003.

[19] R. Wang, "Influence of ultrasound on pitting corrosion and crevice corrosion of SUS304 stainless steel in chloride sodium aqueous solution," Corrosion Science, vol. 50, no. 2, pp. 325-328, 2008.

[20] R. Wang, "Effect of ultrasound on initiation, growth and repassivation behaviours of pitting corrosion of SUS 304 steel in $\mathrm{NaCl}$ aqueous solution," Corrosion Engineering, Science and Technology, vol. 51, no. 3, pp. 201-210, 2016.

[21] R. Wang and M. Kido, "Influence of input power to vibrator and vibrator-to-specimen distance of ultrasound on pitting 
corrosion of SUS304 stainless steel in 3.5\% chloride sodium aqueous solution," Corrosion Science, vol. 51, pp. 1604-1610, 2009.

[22] G. T. Burstein, P. C. Pistorius, and S. P. Mattin, "The nucleation and growth of corrosion pits on stainless steel," Corrosion Science, vol. 35, no. 1-4, pp. 57-62, 1993.

[23] Q. Zhang, R. Wang, M. Kato, and K. Nakasa, "Observation by atomic force microscope of corrosion product during pitting corrosion on SUS304 stainless steel," Scripta Materialia, vol. 52, no. 3, pp. 227-230, 2005.

[24] S. Jafarzadeh, Z. Chen, J. Zhao, and F. Bobaru, "Pitting, lacy covers, and pit merger in stainless steel: $3 \mathrm{D}$ peridynamic models," Corrosion Science, vol. 150, pp. 17-31, 2019.

[25] R. Wang and K. Nakasa, "Effect of ultrasonic wave on the growth of corrosion pits on SUS304 stainless steel," Materials Transactions, vol. 48, no. 5, pp. 1017-1022, 2007.

[26] D. Sun, Y. Jiang, Y. Tang et al., "Pitting corrosion behavior of stainless steel in ultrasonic cell," Electrochimica Acta, vol. 54, no. 5, pp. 1558-1563, 2009.

[27] G. O. H. Whillock and B. F. Harvey, "Ultrasonically enhanced corrosion of 304L stainless steel II: the effect of frequency, acoustic power and horn to specimen distance," Ultrasonics Sonochemistry, vol. 4, no. 1, pp. 33-38, 1997.

[28] G. O. H. Whillock and B. F. Harvey, "Ultrasonically enhanced corrosion of $304 \mathrm{~L}$ stainless steel I: the effect of temperature and hydrostatic pressure," Ultrasonics Sonochemistry, vol. 4, no. 1, pp. 23-31, 1997.

[29] G. O. H. Whillock and B. F. Harvey, "Preliminary investigation of the ultrasonically enhanced corrosion of stainless steel in the nitric acid/chloride system," Ultrasonics Sonochemistry, vol. 3, no. 2, pp. S111-S118, 1996.

[30] B.-C. Wang and J.-h. Zhu, "Influence of ultrasonic cavitation on passive film of stainless steel," Ultrasonics Sonochemistry, vol. 15, no. 3, pp. 239-243, 2008.

[31] O. Lavigne, Y. Takeda, T. Shoji, and K. Sakaguchi, "Water irradiation by high-frequency ultrasonic wave: effects on properties of passive film formed on stainless steel," Ultrasonics Sonochemistry, vol. 18, no. 6, pp. 1287-1294, 2011.

[32] T. Wan, N. Xiao, H. Shen, and X. Yong, "The effect of chloride ions on the corroded surface layer of $00 \mathrm{Cr} 22 \mathrm{Ni} 5 \mathrm{Mo} 3 \mathrm{~N}$ duplex stainless steel under cavitation," Ultrasonics Sonochemistry, vol. 33, pp. 1-9, 2016.

[33] Q. Wang, N. Kawagoishi, and Q. Chen, "Effect of pitting corrosion on very high cycle fatigue behavior," Scripta Materialia, vol. 49, no. 7, pp. 711-716, 2003.

[34] M. Luquedecastro and F. Priegocapote, "Ultrasound-assisted crystallization (sonocrystallization)," Ultrasonics Sonochemistry, vol. 14, no. 6, pp. 717-724, 2007.

[35] G. Vasyliev and M. Pidburtniy, "Influence of ultrasonic vibration on corrosion resistance of austenitic steel," Materials Today: Proceedings, vol. 6, pp. 158-163, 2019.

[36] G. S. Vasyliev, A. A. Novosad, M. O. Pidburtnyi, and O. M. Chyhryn, "Influence of ultrasound vibrations on the corrosion resistance of heat-exchange plates made of AISI 316 steel," Materials Science, vol. 54, no. 6, pp. 913-919, 2019.

[37] J. V. Carstensen, H. Mayer, and P. Brøndsted, "Very high cycle regime fatigue of thin walled tubes made from austenitic stainless steel," Fatigue \& Fracture of Engineering Materials \& Structures, vol. 25, no. 8-9, pp. 837-844, 2002.

[38] D. Kong, C. Dong, Z. Zheng et al., "Surface monitoring for pitting evolution into uniform corrosion on $\mathrm{Cu}-\mathrm{Ni}-\mathrm{Zn}$ ternary alloy in alkaline chloride solution: ex-situ LCM and in-situ SECM," Applied Surface Science, vol. 440, pp. 245-257, 2018.
[39] D. Kong, C. Dong, X. Wei et al., "Size matching effect between anion vacancies and halide ions in passive film breakdown on copper," Electrochimica Acta, vol. 292, pp. 817-827, 2018.

[40] W. Tian, S. Li, N. Du, S. Chen, and Q. Wu, "Effects of applied potential on stable pitting of 304 stainless steel," Corrosion Science, vol. 93, pp. 242-255, 2015.

[41] M. B. Ranade, "Adhesion and removal of fine particles on surfaces," Aerosol Science and Technology, vol. 7, no. 2, pp. 161-176, 1987.

[42] J. Visser, "Particle adhesion and removal: a review," Particulate Science and Technology, vol. 13, no. 3-4, pp. 169-196, 1995.

[43] K. Hein, T. Hucke, M. Stintz, and S. Ripperger, "Analysis of adhesion forces between particles and wall based on the vibration method," Particle \& Particle Systems Characterization, vol. 19, no. 4, pp. 269-276, 2002. 